\title{
Introduction to Selected Contributions from the 47th US Rock Mechanics/Geomechanics Symposium Held in San Francisco, California from June 23-26, 2013
}

\author{
Alvin C. Chan · Joseph P. Morris • \\ Laura J. Pyrak-Nolte
}

Published online: 10 August 2014

(C) Springer-Verlag Wien 2014

This special issue of Rock Mechanics and Rock Engineering contains ten papers that are a representative sample of contributions from the 47th US Rock Mechanics/Geomechanics Symposium held in San Francisco, California from June 23-26, 2013. This multidisciplinary international annual meeting of the American Rock Mechanics Association (ARMA) is a focal event for the Rock Mechanics and Geomechanics community, bringing together professionals and students from civil, geological, mining, geophysical and petroleum engineering.

The Symposium focused on recent advances in rock mechanics and geomechanics that cut across disciplines and spanned the globe with more than half of the papers from 38 countries outside the US. The technical sessions spanned a range of topics from civil, mining and petroleum engineering as well as cross-disciplinary topics that involve experts from many branches of science and engineering.

The characterization and mechanics of fractures are a common theme among many of the papers in this issue with a diversity of tools and approaches being applied. While several authors focused upon experimental studies of the mechanics of fractures and coupled processes within them others utilized novel combinations of theory and computation to shed light upon the behavior of fractures all the way from laboratory to field scales.

In addition, the topics discussed include everything from more familiar rock mechanics concepts such as rock mass characterization and stabilization to the application of mathematical concepts such as percolation theory to the scaling of mechanical and hydraulic properties.

The papers contained in this special issue were selected by members of the Organizing Committee of the 47th US Rock Mechancis/Geomechanics Symposium based on the quality of the technical content of the symposium papers. All papers were expanded and rewritten, then re-reviewed for this special issue.

\footnotetext{
A. C. Chan

Shell Exploration and Production Company,

New Orleans, LA, USA

J. P. Morris

Schlumberger Limited, Schlumberger-Doll Research Center, Cambridge, MA 022139, USA
}

L. J. Pyrak-Nolte ( $\square)$

Purdue University, West Lafayette, IN 47907, USA

e-mail: 1jpn@purdue.edu 